\title{
Diminished Rice Yield by Coupled Impact of Climate Change and Soil Arsenic Contamination
}

\author{
Tianmei WAnG ${ }^{1}$, E. MARIE MueHE ${ }^{1,2}$, AND ScOtT \\ FENDORF $^{1}$ \\ ${ }^{1}$ Stanford University, Stanford, CA-94305, USA \\ ${ }^{2}$ University of Tuebingen, Tuebingen, Germany
}

Rice is an important staple crop for more than half of the world's population. Soils used for rice cultivation within South and Southeast (S/SE) Asia are derived from Himalayan sediments bearing geogenic arsenic (As). Arsenic is also constantly building up in rice paddies through irrigation with groundwater. Arsenic taken up by rice plants dramatically decreases grain yield and is considered a human carcinogen. Our previous studies show climatic stressors coupled with soil As will substantially decrease rice yields and jeopardize grain quality for Californian rice grown in Californian soils. Whether these findings hold true at a global scale, with different soil types and rice varieties, and especially in Asia where $95 \%$ of global rice is grown, remains unknown.

In this study, we investigated 1) how the bioavailability of As changes in Bangladeshi paddy soils under changing climatic conditions, and 2) the coupled impact that climatic and soil arsenic stressors have on the yield and quality of the Bangladeshi rice variety IR 64. We conducted highlycontrolled greenhouse experiments with different soil arsenic concentrations and climatic conditions projected for the year 2100 according to the RCP8.5 in the 5th assessment report of the Intergovernmental Panel on Climate Change (IPCC). We show increased dissolved arsenic under future climatic conditions; arsenic levels increase in the soil solution sharply at the vegetative stage of plant growth and remained high until harvest. Increased soil arsenic levels alone decreased rice height and aboveground green biomass. In combination with future climatic conditions, tiller and panicle development accelerated but with decreased grain filling.

Our findings show large yield decreases and degradation of grain quality under future conditions for major rice growing regions, threatening global food security. 